\title{
Acceptability and accessibility of condom among men who have sex with men (MSM) in Imo state, Nigeria
}

\author{
Udujih OG ${ }^{1}$, Chibueze CV ${ }^{1}$, Udujih $\mathrm{HI}^{2}{ }^{2}{ }^{*}$, Emeruwaonu $\mathrm{CN}^{3}$, Iwuala CC ${ }^{1}$ and Dozie UW ${ }^{1}$ \\ ${ }^{1}$ Department of Public Health, School of Health Technology, Federal University of Technology Owerri. \\ ${ }^{2}$ Department of Medical Laboratory Science, Faculty of Health Science, Imo State University Owerri. \\ ${ }^{3}$ Rural Health Foundation (RHF) Owerri, Imo State.
}

Magna Scientia Advanced Research and Reviews, 2021, 01(02), 024-030

Publication history: Received on 10 January 2021; revised on 20 January 2021; accepted on 22 January 2021

Article DOI: https://doi.org/10.30574/msarr.2021.1.2.0004

\begin{abstract}
HIV prevalence among high risk populations globally is substantially higher than in the general population though men who have sex with men continue to bear a high burden of the infection. The aim of this study was to determine the acceptability and accessibility of condoms among men who have sex with men in Imo State, Nigeria. Hundred and ninety five respondents functional in key population (KP) hot spots in presumptively selected Local Government Areas in the state were randomly selected. Semi-structured questionnaires were used for data collection and data obtained was analyzed using SPSS statistical package version 21. The result showed that 101(51.8\%) of MSM had used condom during a sexual intercourse. Majority 97(50.3\%) indicated that they would not use a condom they love or are in partnership with whereas $69(35 \%)$ used condom occasionally during intercourse. Majority of the respondents 103(52.8\%) have practiced unprotected anal sex within the past six months prior to survey. The major constraint to condom accessibility was reported to be cost (26.3\%). Other constraints to accessibility include condom prejudice $(25.0 \%)$ and setting of residence (24.5\%). Statistically, the study revealed no association between condom uptake and acceptability $(\mathrm{P}=0.001)$ however, there was an association between condom uptake and accessibility $(\mathrm{P}=0.594)$. Interventions targeted at the key population to evaluate trends in sexually transmitted diseases especially HIV as well as improvement of condom accessibility cannot be over emphasized.
\end{abstract}

Keywords: Accessibility; Acceptability; MSM; Imo State; Nigeria

\section{Introduction}

Most significant increases for both STI and HIV have been reported in different countries in Men who have Sex with Men (MSM) groups, largely due to a decrease in the use of condoms for anal sex. Key strategies to reduce HIV transmission among MSM rely on promoting HIV testing and condom use. Condoms, if used correctly and consistently, prevent infection with HIV/AIDS and other sexually transmitted diseases (Alkaiyat et al., 2014; Ayoola, Sekoni, \&Odeyemi, 2013). It is possible that HIV infection among MSM can be mitigated by understanding the risk-related behaviors and unmet needs and allocating appropriate resources for a comprehensive intervention package. High risk groups (HRGs) or Key population are very important sub-groups for the spread of HIV infection as well as for control of the epidemics.

The global pandemic of HIV and other Sexually Transmissible Infections (STIs) necessitates an accelerated emphasis on correct and consistent male condom use. According to global health organizations, 'The male latex condom is the single, most efficient, available technology to reduce the sexual transmission of HIV and other Sexually Transmitted Infections.' However, condom effectiveness is compromised by user errors and lack of use. The gap between perfect and typical use

${ }^{*}$ Corresponding author: Udujih hi

Department of medical laboratory science, faculty of health science, imo state university owerri.

Copyright $(2021$ Author(s) retain the copyright of this article. This article is published under the terms of the Creative Commons Attribution Liscense 4.0. 
has similar relevance for HIV and STI prevention, suggesting that millions of infections could be avoided by improved user effectiveness. (Sanders et al., 2012)

Condoms have been identified by many public health professionals, including the World Health Organization (WHO),' as an important component in the strategy to prevent the further transmission of Human Immunodeficiency Virus (HIV). Investigators have demonstrated that latex condoms are capable of preventing the transmission of several viral pathogens in vitro, including herpes simplex virus, cytomegalovirus, hepatitis B virus, and most especially the Human Immunodeficiency Virus. Although condoms are not considered to be 100 percent effective in interrupting the transmission of HIV, there is a consensus that their appropriate and consistent use could have a major impact on diminishing the spread of AIDS (acquired immunodeficiency syndrome).(Valdiserri et al., 1988). This study aims at providing a population based estimates of the level of acceptability, accessibility and uptake of condom use in the MSM community in Imo state to increase the knowledge base of the evolving HIV epidemic among MSM, and to highlight risk factors and unmet needs that may fuel the epidemic within the MSM communities and their linkages to the general population.

\section{Methods}

The study was carried out in Key Population (KP) mapped out hotspots in Owerri, Orlu and Okigwe senatorial zones and KP based Organizations active in Imo state, Nigeria with reference to Men who have Sex with Men (MSM) community. The KP hot spots are specific location or area where members of key population gather to meet. The research survey was conducted through Rural Health Foundation (RHF), a registered Non-Governmental Organization (NGO) in Nigeria.

\subsection{Study design}

This study adopted a population based survey, descriptive cross sectional design applying the mode of a questionnaire in a key population (KP) community. This is aimed at collecting data specifically on the opinions, acceptance, attitudes and views of the subjects or correspondence on the Acceptability, Accessibility of Condom Use among MSM in Imo state.

\subsection{Study population}

The MSM community is a very sensitive and highly mobile community where maximum trust and confidentiality is required to access this community. The social climate of stigma and discrimination against MSM is one of the reasons this community is less likely to receive appropriate prevention services, access HIV/AIDS commodities, putting them at increased risk of HIV/AIDS.

The respondents for this research work were reached at the mapped out MSM hot spots (Confirmed hide outs) in Imo state and MSM who accessed health care at RHF facility, MSM working and partnering with KP based organizations and MSM recruited by their peers of which Young Men who have Sex with Men (YMSM) are included.

Within two (2) months of the research study, about 195 MSM in total was reached randomly selected from the mapped MSM hot spots in the various LGAs making up the 3 senatorial zones of Imo state. For the sake of this study, a population of 195 was employed. The MSM community has no definite population size in Imo state. Therefore, the sample size employed was determined using the Fishers Method Formula.

\subsubsection{Sampling Methods}

In this study, the purposive and stratified simple random sampling technique was applied for effective execution of the research.

The purposive sampling method was used to purposely and carefully select local government areas, villages and cities with very high number of Mapped MSM hot spots to enable the research have access to a good number of MSM residing and operating in that area. The stratified simple random sampling technique was used to group the remaining areas into Rural and Urban communities and thus selected at random to ensure even distribution and collection of data in the MSM communities in the three (3) senatorial areas of Imo state.

\subsection{Instruments for data collection}

A pre - tested structured questionnaire designed to extract information on the Acceptability and Accessibility of condom use among MSM in Imo state was used as an instrument for data collection. The questionnaire was structured to obtain 
information on Socio - demographic characteristics; age, gender role and occupation and monthly income. The gender roles of the participants was recorded as Top (Penetrative anal sex) and Bottom (Receptive anal sex).

The research questionnaire was administered to the respondents through the Program team of RHF, Inter personal communicators (IPC) working directly with these MSM, MSM Community leaders and the staff workers of KP based organizations functional in Imo state. This was done after obtaining an informed consent. The correspondents (MSM) were extensively enlightened on the relevance of the study and assured of maximum confidentiality. The data collected was analyzed using the Specific Package for Social Sciences (SPSS) Version 21

\section{Results}

\subsection{Socio-Demographic Characteristics of Respondents}

Majority of the respondents 99 (50.8\%) live in urban area of Imo state, while 96(49.2\%) lives in the rural area of Imo state. The occupation of the respondents showed that, majority $72(36.9 \%)$ were into businesses, followed by $65(34.4 \%)$ of students, while the least $56(28.7 \%)$ were civil servants. The educational level of respondents show that $46(23.6 \%)$ had no formal education, 50(25.6\%) had primary education, $48(24.6 \%)$ had secondary education while those with tertiary education $51(26.2 \%)$ were the highest represented in this study. The marital status of the respondents showed that $72(36.9 \%)$ were married, $51(26.2 \%)$ were divorced and the rest $72(36.9 \%)$ were single. Most of the respondents $48(24.6 \%)$ were between the age range of $30-39$ years, followed by those $20-29$ years 47 (24.1\%), age $\geq 40$ years 35 $(17.9 \%)$, while those between $15-19$ years 31 (15.9\%) had the least number of respondents (Table 1)

Table1 Socio-Demographic Characteristics of Men Who Have Sex with Men (MSM) In Imo State

\begin{tabular}{|l|l|l|}
\hline Socio-Demographic Characteristics & Frequency (N = 195) & Percent (\%) \\
\hline Place of Residence & & \\
\hline Urban & 99 & 50.8 \\
\hline Rural & 96 & 49.2 \\
\hline Occupation & & \\
\hline Student & 67 & 34.4 \\
\hline Business & 72 & 36.9 \\
\hline Civil Servant & 56 & 28.7 \\
\hline Education Attainment & & \\
\hline Tertiary & 48 & 24.6 \\
\hline Secondary & 51 & 26.2 \\
\hline Primary & 46 & 23.6 \\
\hline No Formal Education & 50 & 25.6 \\
\hline Marital Status & & \\
\hline Single & 72 & 36.9 \\
\hline Married & 72 & 36.9 \\
\hline Divorced & 51 & 26.2 \\
\hline Age & & \\
\hline$\leq 14$ & 34 & 17.4 \\
\hline $15-19$ & 31 & 15.9 \\
\hline $20-29$ & 47 & 24.1 \\
\hline $30-39$ & 48 & 24.6 \\
\hline$\geq 40$ & 35 & \\
\hline & & \\
\hline
\end{tabular}


The gender role of respondents indicated that, 67(35\%) played the insertive role (Top) during anal intercourse, 65 (335\%) of the MSMs played the receptive role (Bottom) while 63 (33\%) played a combination of the two gender roles (Both) during anal intercourse (Figure 1)

The average monthly income of respondents ranged from 18,000 (\$45.57) to 100,000( $\$ 258.73$ ) Naira with majority 56 $(21.5 \%)$ earning 51,000 (\$131.95)-99,000(\$256.14) Naira, followed by $50(25.6 \%)$ who earned 19,000(\$49.16)$50,000(\$ 129.36)$ Naira and $45(23.1 \%)$ earned more than 100,000(\$258.73)Naira, while the least was $42(27.8 \%)$ earned less than 18,000 (\$45.57) Naira (Figure 2).

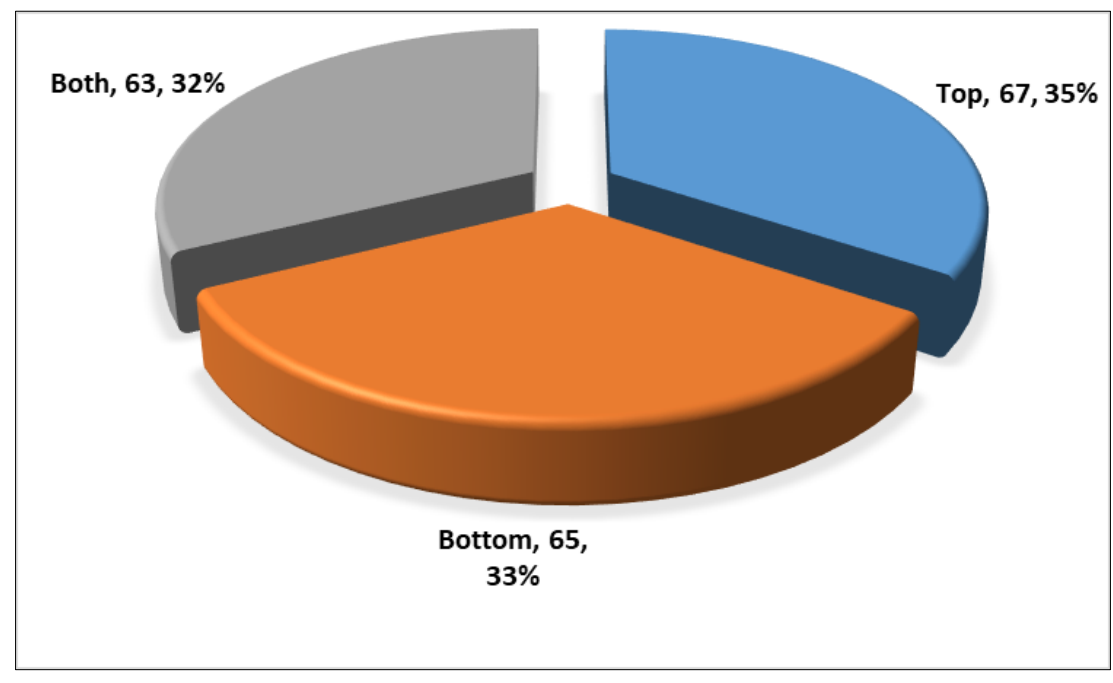

Figure 1 Gender roles of Respondents

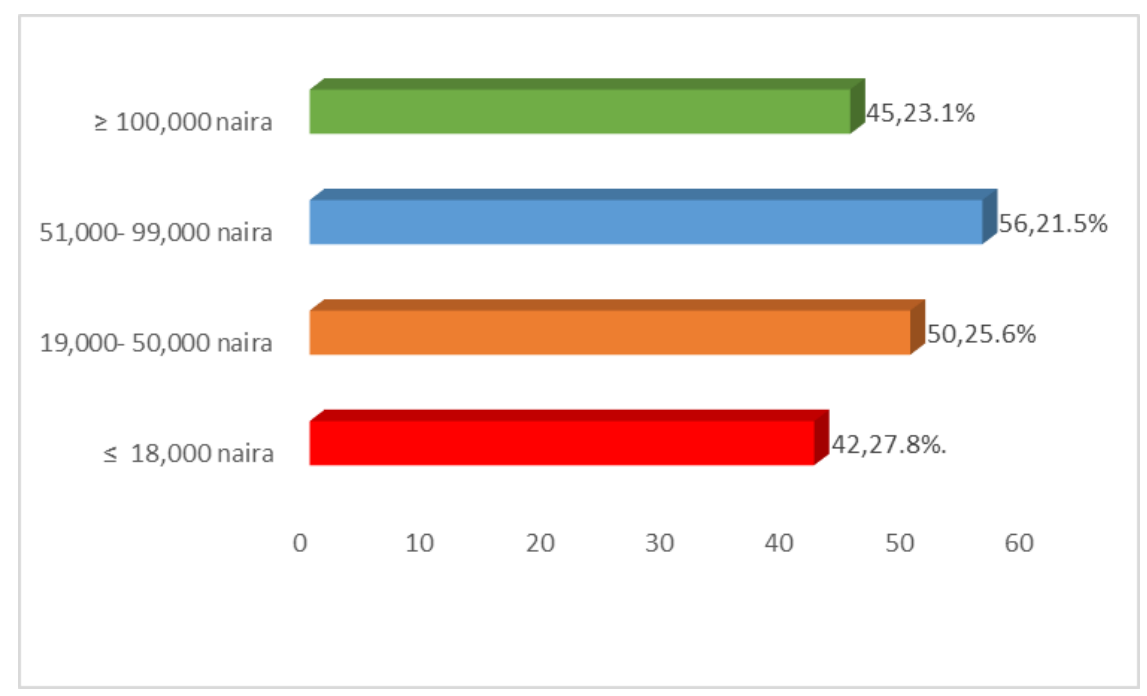

Figure 2 Monthly Income of Respondents

\subsection{Condom acceptability}

Majority 122(62.6\%) of respondents knew about condom, 106(54.4\%) have seen condom, 100(51.3\%) knew about female condom while $122(62.6 \%)$ do not believe that condoms are only used to protect against pregnancy. A total of $112(57.4 \%)$ agreed that condoms should be used during anal intercourse, 101(51.8\%) had used condom during their anal intercourse whereas $102(52.3 \%)$ indicated that they and their partner had used a female condom during anal intercourse. Majority 97(50.3\%) indicated that they would not use a condom for a partner they love or in relationship with. 


\subsection{Condom accessibility}

Out of the 195 respondents, majority 102 (53\%) were of the opinion that condoms are not affordable while 92(47\%) revealed that condoms are affordable. Sixty eight (34\%) respondents were of the opinion that condoms are easy to obtain. A total of $98(19.30 \%)$ respondents obtain condoms from friends/peers, $20.6 \%$ of respondents obtain condoms from health centers / NGOs, $92(18.10 \%)$ of respondents use the pharmacy/chemist shop as their main source of obtaining condoms, 112(22.0\%) of respondents patronize road side kiosks while 102(20.0\%) of respondents consent to obtaining condoms from retail shops/ supermarkets (Table 2)

Table 2 Condom Acceptability and Uptake among Men Who Have Sex with Men (MSM) In Imo State

\begin{tabular}{|c|c|c|}
\hline Response & Frequency $(\mathrm{N}=195)$ & Percentage (\%) \\
\hline \multicolumn{3}{|c|}{ Knowledge of condoms } \\
\hline Yes & 122 & 62.6 \\
\hline No & 73 & 37.4 \\
\hline \multicolumn{3}{|c|}{ Ever seen a condom } \\
\hline Yes & 106 & 54.4 \\
\hline No & 89 & 45.6 \\
\hline \multicolumn{3}{|c|}{ Knowledge of female condoms } \\
\hline Yes & 100 & 51.3 \\
\hline No & 95 & 48.7 \\
\hline \multicolumn{3}{|c|}{ Believe that condoms are ONLY used to protect against pregnancy } \\
\hline Yes & 73 & 37.4 \\
\hline No & 122 & 62.6 \\
\hline \multicolumn{3}{|c|}{ Perception about condom use during anal intercourse } \\
\hline Yes & 112 & 57.4 \\
\hline No & 83 & 42.6 \\
\hline \multicolumn{3}{|c|}{ Use of condom during anal intercourse } \\
\hline Yes & 101 & 51.8 \\
\hline No & 94 & 48.2 \\
\hline \multicolumn{3}{|c|}{ Assessment of condom comfort and pleasure } \\
\hline Yes & 100 & 51.3 \\
\hline No & 95 & 48.7 \\
\hline \multicolumn{3}{|c|}{ Use of Female Condom during anal intercourse } \\
\hline Yes & 102 & 52.3 \\
\hline No & 93 & 47.7 \\
\hline \multicolumn{3}{|c|}{ Use of condom for a partner you are in Love with or in a Relationship with } \\
\hline Yes & 97 & 49.7 \\
\hline No & 98 & 50.3 \\
\hline \multicolumn{3}{|c|}{ Use of condom at first anal intercourse } \\
\hline Yes & 64 & 32.8 \\
\hline No & 69 & 35.4 \\
\hline
\end{tabular}


Major constraint to obtaining condoms reported where cost of condom 102(26.30\%), condom prejudice $97(25.0 \%)$, setting of the area of residence $95(24.50 \%)$ which could be urban or rural settlement and $94(24.20 \%)$ of the respondents indicated other constraints to be religious beliefs.

\section{Discussion}

The recruitment of MSM for studies is a challenge for researchers because no sampling frame exists for MSM and public acknowledgement of membership may also be stigmatized in some cases (Carballo-Diegues et al., 2011). There is paucity of data on men who sleep with men (MSM) in Imo State. Studies are limited because conventional sampling misses MSM and some HIV-Positive MSM who are at high risk for transmission of HIV or STDs may not go to sampling centers (Yang et al, 2014) or divulge information about their sexual preferences. This study however, showed that majority $99(50.8 \%)$ of the respondents in this study live in urban areas of Imo state, while $96(49.2 \%)$ live in the rural areas of Imo state with majority $48(24.6 \%)$ between the age range of 30-39 years. This age range is active members of the labor force making them financially independent to pursue their sexual desires which may include obtaining sex for money. In addition, the members of this age group are highly sexually active making them a possible high risk group for the transmission of HIV and STDs among MSM.

MSM do not constitute a uniform group of people, it includes self - identified gay and bisexual mem, men who do not accept their gender and self identify as women, men who engage in male-male sex and self-identify as heterosexual (Ayoola et al., 2013). In this study, the marital status of the respondents showed that $72(36.9 \%)$ were married. This explains the major link to the spread of HIV and other STI from the MSM community to the general community (Xing et al., 2008).

It was revealed in this study that, 67(35\%) of the MSM played the insertive role (Top) during anal intercourse, whereas $65(335 \%)$ played the receptive role (Bottom) and 63 (33\%) played a combination of the two gender roles during anal intercourse similar to the findings of Heeren et al (2007).

\subsection{Acceptability of condom among respondents}

A higher percentage 106(54.4\%) of MSM have adequate knowledge of condoms as a protective device and have seen a condom. A higher percentage 100(51.3\%) also knew about female condom. The study revealed a high level of condom acceptability with $112(57.4 \%)$ of respondents accepting that condoms should be used during anal intercourse. This is similar to the findings of Ayoola et al (2013) who recorded consistent condom use among 40.5\% of MSM in Lagos, Nigeria.

\subsection{Accessibility of condom among respondents}

Out of the 195 respondents, majority 102 (53\%) were of the opinion that condoms are not affordable while 68 (34\%) of the respondents proposed that condoms are not easy to obtain. This is very similar to a study conducted on MSM in Lagos (Ayoola et al., 2013). This in turn, explains the reason why most MSM (22.0\%) patronize road side kiosks as their main source of obtaining condoms in a bid to purchase condoms at cheaper rates thereby settling for either fake or expired condoms. This however, encourages the spread of HIV/AIDS due to condom tear or breakage.

Condom prejudice 97 (25.0\%) and cost 102 (26.30\%) were the major constraint to obtaining condoms. This is similar to the findings of Yang et al (2014). Programs targeted at awareness and free distributions of condoms have been reported to increase condom accessibility (Ramanathan et al., 2014).

\section{Conclusion}

Consistent condom use is effective in reducing sexually transmitted diseases of which HIV is among. MSM engage in high risk sexual behaviors such as unprotected receptive and insertive anal sex and multiple sexual partnerships in the absence of consistent condom use. It is well known that multiple sexual partners and high-risk sexual behaviours such as unprotected penile-anal sexual intercourse increase the risk of HIV acquisition. MSM who also have female sexual partners are possible agents of widespread transmission of HIV to the general population hence, there is an urgent need to improve HIV prevention through targeted programs that would improve accessibility and acceptability across Imo state and Nigeria at large. 


\section{Compliance with ethical standards}

\section{Acknowledgments}

We wish to acknowledge Rural Health Foundation (RHF) for their support during the course of this study.

\section{Disclosure of conflict of interest}

We declare that there is no conflict of interest in this study.

\section{Statement of informed consent}

Informed consent was obtained from all individual participants included in the study.

\section{References}

[1] Alkaiyat A, Schaetti C, Liswi M, Weiss MG. Condom use and HIV testing among men who have sex with men in Jordan. Journal of the International AIDS Society. 2014; 17(1): 18573.

[2] Ayoola 00, Sekoni AO, Odeyemi KA. Transactional sex, condom and lubricant use among men who have sex with men in Lagos State, Nigeria. African journal of reproductive health. 2013; 17(4): 90-98.

[3] Sanders SA, Yarber WL, Kaufman EL, Crosby RA, Graham CA, Milhausen RR. Condom use errors and problems: a global view. Sexual health. 2012; 9(1): 81-95.

[4] Valdiserri RO, Lyter D, Leviton LC, Callahan CM, Kingsley LA, Rinaldo CR. Variables influencing condom use in a cohort of gay and bisexual men. American Journal of Public Health. 1988; 78(7): 801-805.

[5] Carballo-Dieguez A, Balan I, Marone R, Dolezal C, Barreda V, Leu CS, Avila Mm. Use of respondent driven sampling (RDS) generates a very diverse sample of men who have sex with men(MSM) in Buenos Aires, Argentina. PLoS One. 2011; 6:e27447.

[6] Yang Z, Zhang S, Dong Z, Jin M, Han J. prevalence of unprotected anal intercourse in men who sleep have sex with men recruited online versus offline. Bio Medical Central Public Health. 2014; 14:508.

[7] Xing JM, Zhang KL, Chen X, Zheng J. A cross- sectional study among men who have sex with men: a comparison of online and offline samples in Human province, china. Chinese Medical Journal (England). 2008; 121:2342-2345.

[8] Heeren GA, Jemmott III JB, Mandeya A, Tyler JC. Theory-Based Predictors of Condom Use among university Students in the United States and South Africa. AIDS Education \& Prevention. 2007; 19(1): 1-12.

[9] Ramanathan S, Deshpande S, Guatum A, Pardeshi D, Ramakrishnan L, Goswan P, Adhikary R, George B, Paranjape RS, Mainkar M. Increase in condom use and decline in prevalence of sexually transmitted infections among highrisk men who have sex with men and transgender persons in Maharashtra, India: Avahan, the India AIDS Initiative. Bio Med Central Public Health. 2014; 14:784. 